\title{
Antibiotic prescribing in general medical and surgical specialties: a prospective cohort study
}

\author{
E. Charani ${ }^{1 *}$ DD, E. de Barra², T. M. Rawson ${ }^{1}$, D. Gill ${ }^{3}$, M. Gilchrist ${ }^{4}$, N. R. Naylor ${ }^{1}$ and A. H. Holmes ${ }^{1}$
}

\begin{abstract}
Background: Qualitative work has described the differences in prescribing practice across medical and surgical specialties. This study aimed to understand if specialty impacts quantitative measures of prescribing practice.

Methods: We prospectively analysed the antibiotic prescribing across general medical and surgical teams for acutely admitted patients. Over a 12-month period (June 2016 - May 2017) 659 patients (362 medical, 297 surgical) were followed for the duration of their hospital stay. Antibiotic prescribing across these cohorts was assessed using Chi-squared or Wilcoxon rank-sum, depending on normality of data. The t-test was used to compare age and length of stay. A logistic regression model was used to predict escalation of antibiotic therapy.

Results: Surgical patients were younger $(p<0.001)$ with lower Charlson Comorbidity Index scores $(p<0.001)$. Antibiotics were prescribed for 45\% (162/362) medical and 55\% (164/297) surgical patients. Microbiological results were available for 26\% (42/164) medical and 29\% (48/162) surgical patients, of which 55\% (23/42) and 48\% (23/48) were positive respectively. There was no difference in the spectrum of antibiotics prescribed between surgery and medicine $(p=0.507)$. In surgery antibiotics were 1$)$ prescribed more frequently $(p=0.001) ; 2)$ for longer $(p=0.016)$; 3) more likely to be escalated ( $p=0.004)$; 4 ) less likely to be compliant with local policy $(p<0.001)$ than medicine.

Conclusions: Across both specialties, microbiology investigation results are not adequately used to diagnose infections and optimise their management. There is significant variation in antibiotic decision-making (including escalation patterns) between general surgical and medical teams. Antibiotic stewardship interventions targeting surgical specialties need to go beyond surgical prophylaxis. It is critical to focus on of review the patients initiated on therapeutic antibiotics in surgical specialties to ensure that escalation and continuation of therapy is justified.
\end{abstract}

Keywords: Antibiotic-decision making, Surgery, Antibiotic escalation

\section{Background}

Evidence suggests that a large proportion of antibiotic prescribing in hospitals may be inappropriate [1-3]. Optimising antibiotic prescribing and reducing the use of broad-spectrum agents has been shown to reduce the occurrence of healthcare associated infections (HCAI) in hospitals [4]. The bulk of antibiotic decision-making in hospitals takes place with no direct input from infectious disease or medical microbiology experts. There are many

\footnotetext{
* Correspondence: e.charani@imperial.ac.uk

${ }^{1} \mathrm{NIHR}$ Health Protection Research Unit in Healthcare Associated Infections and Antimicrobial Resistance, Hammersmith Campus, Imperial College London, 8th Floor Commonwealth Building, Du Cane Road, London W12 ONN, UK

Full list of author information is available at the end of the article
}

branches of specialism in medical practice [5] with one of the most important being between surgery and medicine. The different cultures and team dynamics across the medical and surgical specialties have been recently described using qualitative methodology [6]. Evidence suggests that antibiotic prescribing in surgery lacks clarity and occurs in the context of disjointed information $[6,7]$. Studies from operating room practices have highlighted how the environment and context can influence surgical outcomes [8]. In the case of surgical prophylaxis, teams have reported that though aware of guidelines and policy, they attribute a low priority to policy adherence [9]. Whilst qualitative research is critical for defining the context in which medical

(C) The Author(s). 2019 Open Access This article is distributed under the terms of the Creative Commons Attribution 4.0 International License (http://creativecommons.org/licenses/by/4.0/), which permits unrestricted use, distribution, and 
decision-making occurs across different specialties, and describes how and why clinicians make antibiotic prescribing decisions, it does not address what the effect of these contextual differences are on clinical practice. In this study we set out to investigate antibiotic prescribing in medical and surgical specialties. Detailing and understanding the real-time clinical patterns of prescribing is critical to the co- design of effective antibiotic optimisation interventions. Though the conditions for which antibiotics are prescribed may differ across specialties, the principles of infection diagnosis and management are the same. This study set out to investigate whether there was significant variation in the antibiotic prescribing practices between surgical and medical teams. This knowledge is critical in order to shift from a one size fits all approach to one that recognizes the specific challenges facing clinicians treating infections across different specialties.

\section{Methods}

\section{Study sample size calculation}

This study was conducted across general medical and general surgical teams in one of the five hospitals of a university affiliated Healthcare NHS Organisation, in London. The hospital selected had the largest Emergency Department (ED) and the highest annual turnover of patients. The hospitals have an established, multidisciplinary antimicrobial stewardship programme (ASP). Studies across the hospitals have previously demonstrated a $10 \%$ difference in compliance to the local antibiotic policy between medical and surgical teams, with medical teams demonstrating a higher rate of concordance [10].

A power calculation for two independent study groups with a dichotomous primary endpoint was carried out [11]. Using point prevalence data, anticipated incidence of compliance to policy was estimated to be $83 \%$ in surgery and $93 \%$ in medicine [10]. Setting the type one error rate to 0.05 , and type two error rate to 0.2 , and thus achieving a statistical power of 0.8 , it was calculated that the study would require 165 patients in each arm.

\section{Exclusion and inclusion criteria}

Between June 2016 - May 2017 adult patients (aged $\geq 18$ years) admitted to the medical and surgical teams and prescribed empiric antibiotics other than for prophylaxis were eligible to be included in the study. Data were collected from each ward on alternate weeks. Patients were prospectively identified on qualitative observations of acute ward rounds as part of a mixed methods study [6, 7]. Patients with a hospital stay less than $24 \mathrm{~h}$, and those from (or transferred to) other specialties were excluded.

\section{Data collection}

This study had a prospective cohort design. The reference group were the medical cohort and the comparison group were the surgical cohort. An accurate assessment of the appropriateness of the prescribed antibiotics requires real-time infectious diseases consultations in parallel to the care provided by the respective teams. In the absence of being able to measure appropriateness, the primary outcome measures selected in this study were compliance to the local antibiotic policy, and changes to antibiotic prescriptions (e.g. escalation or de-escalation). The secondary outcome measures were, duration of antibiotic prescriptions, length of hospital stay, use of microbiology and radiology to guide therapy, and 30-day readmission. Patient demographics, antibiotic prescriptions and corresponding indications, and inflammatory marker results were obtained from the patient notes. One researcher (EC) collected all the data. A single reading of white cell count, C-reactive protein, and temperature, closest to the time of initiating antibiotic therapy were recorded. Procalcitonin is not routinely tested for patients in this hospital. The International Classification of Diseases, tenth revision (ICD-10) coding was used to calculate the age-adjusted Charlson comorbidity index (ACCI) for subjects [12]. Comorbidity was ranked by using the final CCI. The CCI score was ranked as: a) $0-2$ low; b) 3-4 moderate; and c) 5 or above, severe [13].

The antibiotic exposure days were measured as the number of days that a patient received one or more systemic antibiotics. The cumulative antibiotics days, where multiple antibiotics prescribed on the same day were counted as multiple antibiotic days, was also measured. Cumulative antibiotic exposure days has been used previously [14], regarding its association with Clostridium difficile infection.

Antibiotics were ranked in ascending order according to their relative activity against drug-resistant organisms [15](Table 1).

Changes made to prescribed antibiotics were classified, using published criteria [16]. Escalation of therapy was defined as the switch to or addition of an agent with a broader spectrum, or additional coverage, or switch from oral to intravenous therapy. De-escalation of therapy was defined as stopping therapy, or de-escalation from intravenous to oral, or changing to an agent with a less broad-spectrum coverage. If antibiotic choice was restricted or changed to broad spectrum agents due to an allergy to a class or individual antibiotic(s), the therapy was classified as unchanged e.g. not de-escalated or escalated.

The following criteria were used to assess whether the antibiotics prescribed were compliant with local empiric policy: 
Table 1 Antibiotic ranking

\begin{tabular}{ll}
\hline Rank 1 & $\begin{array}{l}\text { Narrow spectrum, including first-generation and second -generation cephalosporins, } \\
\text { amoxicillin, co-trimoxazole, metronidazole, and oral vancomycin; }\end{array}$ \\
Rank 2 & $\begin{array}{l}\text { Broad spectrum, including flouroquinolones, macrolides, third-generation cephalosporins, } \\
\text { co-amoxiclav, clindamycin; }\end{array}$ \\
Rank 3 & $\begin{array}{l}\text { Extended spectrum, including antipseudomonal penicillins, antipseudomonal carbapenems } \\
\text { and intravenous vancomycin; }\end{array}$ \\
Rank 4 & Restricted, including colistin, tigecycline, linezolid, and daptomycin \\
\hline
\end{tabular}

- Was the indication documented on the electronic chart or the medical notes?

- Did the indication have a matching recommendation in the policy?

- If there was no recommendation in the policy, was there any infection team input?

For cases where the indication was missing or vague e.g. 'for infection', this variable was labelled as unclear. The reason for having an unclear category as opposed to missing data was to identify cases where the antibiotic prescription had been prescribed and no indication recorded in the notes or the medication chart. One of the requirements of the policy is that for all therapeutic courses of antibiotics, there should be an indication recorded. If antibiotic therapy did not match the recommendation in the policy for the recorded indication, and there was no infection team input, it was labelled as non-compliant.

\section{Data analysis}

The analysis was carried out using Stata, (StataCorp, College Station, Texas, US) version 13.1. Variation in the descriptive variables between the cohorts was assessed using Chi- squared or Wilcoxon rank-sum, depending on normality of data. An independent t-test was used to determine if there were statistical differences in the age and length of stay of patients in the cohorts. We created a logistic regression model to understand the predictors of antibiotic prescribing (as measured by escalation) and see whether there were differences between the two groups after adjusting for these. Escalation was the measure used in the model as deviations from policy can often have a legitimate reason, and hence compliance to policy was not deemed an appropriate measure of the quality of antibiotic prescribing. The variables specialty, length of stay, ACCI, positive chest X-ray and microbiological results were selected as predictors based on existing literature and discussions with the clinicians [6]. The length of stay, antibiotic exposure days, and the comorbidity index were fitted as categorical variables in the model, as they were skewed in their distributions. Statistical significance was defined as a $p \leq 0.05$. The length of stay and ACCI were tested in the regression model as both continuous and categorical variables. In both cases, the scaling (i.e. variable) type with the best fit was categorical. In the final analysis, these two variables were fitted as categorical.

\section{Results}

\section{Descriptive statistics}

All subjects had complete data for the variables included in this study. The teams admitted 659 patients (362 in medicine and 297 in surgery) during the study period (Fig. 1). One surgical and 6 medical patients were excluded from the statistical analysis in this study (reasons detailed in Fig. 1). Of the included patients, 162 (45\%) in medicine, and 164 (55\%) in surgery were receiving at least one course of therapeutic antibiotics. During the ward rounds observed in the study, prescribed antibiotics were reviewed in 143/162 (88\%) of medical and 111/164 (68\%) of surgical patients.

At the time of initiating antibiotics, a normal white cell count was present in 76/162 (47\%) of medical, and 52/ $164(32 \%)$ of surgical patients (Table 2). Antibiotics were started in the absence of a) fever and b) abnormal white blood cell count in 32/162 (19\%) of medical and 32/164 (19\%) of surgical patients. C-reactive protein was recorded as high, or rising in 308/326 (95\%) patients across both specialties. Radiological data in the form of chest $\mathrm{x}$-ray, was available for 90/162 (55\%) medical and in $64 / 164$ (39\%) surgical patients. In medicine, 36/162 (22\%), and in surgery $17 / 164(10 \%)$ patients had infection confirmed in the radiological report accompanying the chest X-ray. Of all the patients receiving antibiotics $23 / 162(14 \%)$ in medicine and 23/164 (14\%) in surgery had a positive microbiological sample.

There were 395 antibiotic prescriptions in medicine and 461 in surgery. These included the same antibiotic given by a different route or on different occasions to the same patient in the same admission spell. Of the prescribed antibiotic courses, 200/395 (51\%) of medical, and 395/461 (86\%) surgical were intravenous. Over half, 90/162 (56\%) of medical patients were initiated on antibiotics for a respiratory infection (Table 3). Urinary tract infections were the second most common indication in medical patients $(29 / 162 ; 18 \%)$. In surgery, intraperitoneal infections e.g. diverticulitis and appendicitis, were the most common indication $(44 / 164 ; 27 \%)$, followed by biliary infections e.g. cholecystitis (39/164; 24\%). Antibiotics 


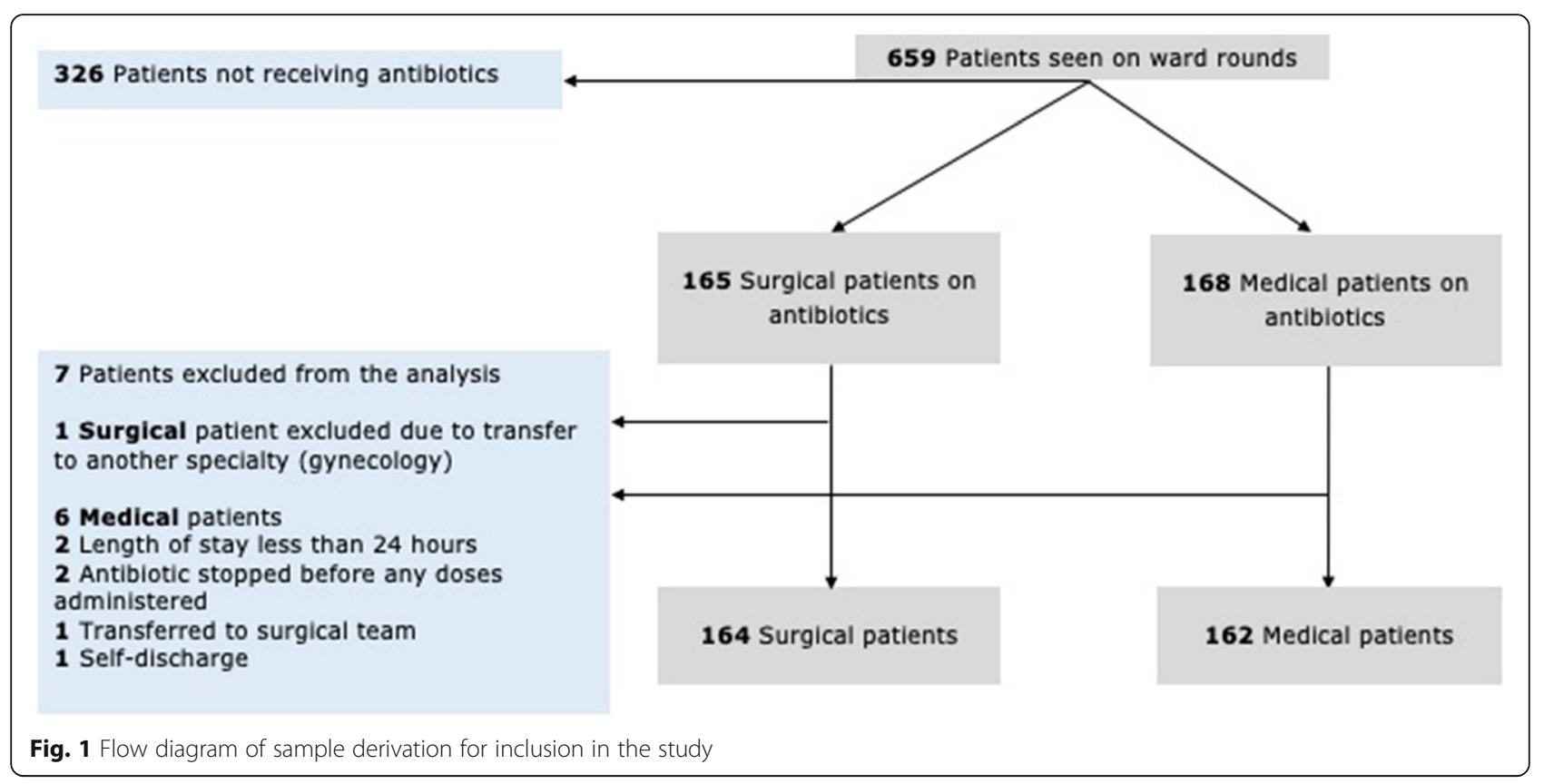

were initiated for suspected sepsis in 14/164 (9\%) surgical and 5/162 (3\%) medical patients. There was no statistically significant difference $(p=0.507)$ in the spectrum and rank of antibiotics that the medical and surgical patients were exposed to during their stay.

The mean length of stay was 11 days $( \pm 1.21)$ in medicine, 16 days $( \pm 1.87)$ in surgery, $\mathrm{t}(324), p=0.0553$ (Table 3$)$. Medical patients had a significantly higher CCI score $(p<0.001)$. Thirty-day readmission to hospital was significantly higher in medicine versus surgery $(p<0.001)$. There was no difference $(p=0.977)$ in mortality during the admission episode in the two groups. Monotherapy, was more likely $(\mathrm{p}<0.001)$ in medicine than surgery, with 36/ $162(22 \%)$ vs. $12 / 164$ (7\%), of patients being treated with one course of antibiotics during their stay, respectively (Table 4). Surgical patients had 50/164 (30\%) cumulative antibiotics days equal to or greater than 15 , compared with $22 / 162(15 \%)$ medical patients $(p=0.016)$. Escalation of the initial antibiotic therapy was more likely in the surgical patients than in medical patients, with 49/164 (30\%) therapy escalations in surgery compared with $31 / 162(19 \%)$ in medicine $(p=0.0037)$.

The lack of a documented indication for prescribed antibiotics made it difficult to assess the compliance to policy for $21 / 164$ (13\%) patients in surgery. When included as a three-category variable (Yes/No/Unclear) there was a statistically significant difference $(p<0.001)$ in compliance to policy between medicine $(131 / 162,80.86)$ and surgery $(108 / 164,65.85)$ (Table 5$)$. In addition to receiving antibiotics during their stay, 80/162 (49\%) medical and 73/ 164 (45\%) surgical patients were subsequently discharged home with a course of antibiotics.
In the logistic regression model, the unadjusted odds ratio of therapy escalation in surgery versus medicine was $1.801,95 \%$ CI $1.071-3.028, P=0.024$. In surgery, $64 / 164(39 \%)$ of patients underwent an operation during their stay. Having an operation (reference set as not having an operation) was associated with increased odds of escalation of antibiotic therapy $(\mathrm{OR}=1.69,95 \% \mathrm{CI}$ $0.939-3.042, p=0.082)$ in the surgical cohort, although this was not statistically significant. In the fully adjusted logistic regression model the odds ratio of antibiotic therapy escalation in surgical patients remained significantly higher compared to medicine $(\mathrm{OR}=1.94,95 \% \mathrm{CI}$ : $1.07-3.53, p=0.03)$. Comorbidity, culture and sensitivity results and signs of infection on chest X-ray did not significantly affect the odds of therapy escalation in the regression model. There was a statistically significant association between length of stay and escalation of therapy (Table 6).

\section{Discussion}

In this study we investigated real-time antibiotic prescribing practices in surgical and medical teams, in order to understand the variation in practice and identify the current gaps. This understanding of the variation in practice across the specialties and teams is necessary, in order to develop bespoke stewardship interventions that target the gaps in practice within specialties. Half the patients received at least one course of antibiotics during their hospital stay. Surgical patients were more likely to receive multiple courses of antibiotics during their hospital stay, and were less likely to have their antibiotic therapy reviewed during ward rounds. The propensity in surgery 
Table 2 Relative frequency of diagnostic information for patients started on antibiotics in medicine, and surgery (normal ranges are those defined in the local laboratory)

\begin{tabular}{|c|c|c|c|}
\hline Diagnostic Information & Total $326 n(\%)$ & Medicine 162 n (\%) & Surgery $164 n(\%)$ \\
\hline \multicolumn{4}{|l|}{ White Cell Count } \\
\hline Normal $\left(4.2-11.2 \times 10^{9} / \mathrm{L}\right)$ & $128(39.3)$ & $76(47.0)$ & $52(31.7)$ \\
\hline Abnormal & $197(60.4)$ & $86(53.0)$ & $111(68.1)$ \\
\hline No Data & $1(0.3)$ & 0 & $1(0.6)$ \\
\hline \multicolumn{4}{|l|}{ Body Temperature } \\
\hline Normal $\left(36.5-37.5^{\circ} \mathrm{C}\right)$ & $168(51.5)$ & $70(43.2)$ & $98(60.0)$ \\
\hline Abnormal & $157(48.2)$ & $91(56.2)$ & $66(40.0)$ \\
\hline No Data & $1(0.3)$ & $1(0.6)$ & 0 \\
\hline \multicolumn{4}{|l|}{ Body temperature and White Cell Count } \\
\hline Normal & $64(19.4)$ & $32(19.4)$ & $32(19.4)$ \\
\hline Abnormal & $260(80.0)$ & $129(80.0)$ & $131(80.0)$ \\
\hline No Data & $2(0.6)$ & $1(0.6)$ & $1(0.6)$ \\
\hline \multicolumn{4}{|l|}{ C-reactive Protein } \\
\hline Normal (<6 mg/L) & $17(5.2)$ & $11(7.0)$ & $6(3.7)$ \\
\hline Abnormal (> 6 mg/L) & $308(94.5)$ & $151(93.0)$ & $157(95.7)$ \\
\hline No Data & $1(0.3)$ & 0 & $1(0.6)$ \\
\hline \multicolumn{4}{|l|}{ Chest X-ray at start of antibiotic } \\
\hline Yes & $154(47.0)$ & $90(55.6)$ & $64(39.0)$ \\
\hline No & $172(53.0)$ & $72(44.4)$ & $100(61.0)$ \\
\hline \multicolumn{4}{|l|}{ Sign of infection on chest $\mathrm{X}$-ray } \\
\hline Yes & $53(16.0)$ & $36(22.0)$ & $17(10.0)$ \\
\hline No & $101(31.0)$ & $54(33.3)$ & $47(29.0)$ \\
\hline No imaging & $172(53.0)$ & $72(44.4)$ & $100(61.0)$ \\
\hline \multicolumn{4}{|l|}{$\begin{array}{l}\text { Microbiological culture collected } \\
\text { before antibiotic initiation }\end{array}$} \\
\hline Yes & $90(27.6)$ & $42(26.0)$ & $48(29.0)$ \\
\hline No & $236(72.4)$ & $120(74.0)$ & $116(71.0)$ \\
\hline \multicolumn{4}{|l|}{$\begin{array}{l}\text { The result of microbiological culture } \\
\text { collected before antibiotic initiation }\end{array}$} \\
\hline No growth (negative culture) & $44(13.5)$ & $19(11.7)$ & $25(15.0)$ \\
\hline Pathogen grown (positive culture) & $46(14.1)$ & $23(14.2)$ & $23(14.0)$ \\
\hline No Culture & $236(72.4)$ & $120(74.1)$ & $116(71.0)$ \\
\hline
\end{tabular}

in this study was to initially prescribe cefuroxime and metronidazole and then step up to intravenous broadspectrum agents e.g. piperacillin/ tazobactam, and coamoxiclav with addition of other agents such as gentamicin and vancomycin. In medicine, broad-spectrum agents were more likely to be initiated upon admission and the focus stewardship efforts should be in the initial phase of the patients' hospital stay. Over the course of the hospital stay however, this study found no statistical difference between the spectrum of antibiotics prescribed in surgery and medicine. This is a new and valuable finding as in surgery, most ASP interventions target surgical prophylaxis or surgical site infection prevention $[17,18]$. In surgery stewardship efforts should be focused on patients who remain in hospital in the post-operative phase where they are likely to be initiated on broad spectrum antibiotics.

Diagnostic tests, though available were not routinely used to rationalise antibiotic prescribing. Two of the key interventions in optimising antibiotic use are obtaining a microbiological culture prior to initiation of antibiotic therapy and ensuring relevant imaging $[4,19]$. One in five of the patients in both specialties were initiated on antibiotics in the absence of fever and raised white cell count, and culture and sensitivity data were only collected from one third of patients initiated on antibiotics. These findings are consistent with studies reporting 
Table 3 Indication for empiric antibiotic course by specialty (* included non-defined infections in surgery and of various organ systems in medicine)

\begin{tabular}{llll}
\hline Indication for antibiotic therapy & Total $326 n(\%)$ & Medicine $162 n(\%)$ & Surgery $164 n(\%)$ \\
\hline Respiratory & $104(31.90)$ & $90(55.56)$ & $14(8.54)$ \\
Urinary tract & $39(11.96)$ & $29(17.90)$ & $10(6.10)$ \\
Intraperitoneal/ Gastrointestinal & $48(14.72)$ & $4(2.47)$ & $44(26.83)$ \\
Skin and soft tissue & $16(4.91)$ & $8(4.94)$ & $8(4.88)$ \\
Sepsis & $19(5.83)$ & $5(3.09)$ & $14(8.54)$ \\
Biliary & $39(11.96)$ & 0 & $39(23.78)$ \\
Other* & $61(18.71)$ & $26(16.05)$ & $35(21.34)$ \\
\hline
\end{tabular}

inappropriate antibiotic use in hospitals and the inadequate use of available diagnostic tests [15, 20-22]. Identifying the causative organism for the infection, through use of laboratory diagnostics, has been shown to be highly effective in optimising antibiotic therapy [23, 24]. Over $95 \%$ of all patients across medicine and surgery had a raised C-reactive protein level at initiation of antibiotic therapy. Published studies have described the role of C-reactive protein in the diagnosis of infections [25, 26], in particular its overuse post-operatively. In post-operative patients C-reactive protein levels can become elevated [26] in response to the trauma of the surgery, and as such the utility of using this marker as a specific marker of infection is inappropriate. Likewise, in medicine the level may be raised due to acute conditions other than infection, such as a myocardial infarct [27-29]. In clinical practice, it is not the absolute $\mathrm{C}$-reactive protein level that should be used, but its trend over time. Large studies on the response of $\mathrm{C}$ reactive protein to antibiotic therapy in infections are lacking [30]. Much work is needed to shift the attitude of healthcare professionals away from their dependency to use C-reactive protein elevation to initiate antibiotics. Clinicians should be encouraged to use their clinical skills for diagnosing infections and to consult with the available pharmacy and infection specialists. Failing that, the routine use of $\mathrm{C}$ reactive protein as a diagnostic marker should be limited.

The surgical patients were primarily receiving intravenous antibiotics. As most of the caseload was intra-abdominal infections the intravenous route is entirely acceptable, especially in patients who have had an operation, and who may have poor gut absorption. Despite these dispensations, only $40 \%$ of the surgical patients underwent an operation, however $86 \%$ of the antibiotic courses in surgery were intravenous. It would be valuable to repeat this study amongst different surgical specialties to see if the use of intravenous route is as prevalent across the different disciplines in surgery. This study found an association between increased length of stay and antibiotic escalation. Several studies have demonstrated an association between reduced length of hospital stay and de-

Table 4 Univariable analysis of demographic outcomes by specialty

\begin{tabular}{|c|c|c|c|c|}
\hline Variable & Measure & Medicine $N=162$ & Surgery $N=164$ & $P$ value* \\
\hline Gender - Male & $n(\%)$ & $76(47)$ & $84(51)$ & 0.441 \\
\hline \multirow[t]{3}{*}{ Age at admission } & Mean (SD) & $70(18)$ & $55(22)$ & - \\
\hline & Median (Interquartile range) & $74(27-93)$ & $55(18-92)$ & $<0.001$ \\
\hline & Range (Minimum - Maximum) & $21-104$ & 18-95 & - \\
\hline \multirow[t]{3}{*}{ Length of Stay } & Mean (SD) & $11(15)$ & $16(24)$ & 0.0553 \\
\hline & Median (Interquartile range) & $7(1-76)$ & $5(2-106)$ & $<0.001$ \\
\hline & Range (Minimum - Maximum) & $1-95$ & $24-160$ & - \\
\hline \multirow{4}{*}{$\begin{array}{l}\text { Charlson comorbidity } \\
\text { index (age adjusted) }\end{array}$} & $n(\%)$ & & & \\
\hline & Low (score of 0-2) & $30(19)$ & $89(54)$ & $<0.001$ \\
\hline & Moderate (score of 3-4) & $39(24)$ & $23(14)$ & \\
\hline & Severe (score of $\geq 5$ ) & $93(57)$ & $52(32)$ & \\
\hline 30 day readmission & $n(\%)$ & $43(27)$ & $29(18)$ & $<0.001$ \\
\hline Mortality in admission episode & $n(\%)$ & $10(6)$ & $10(6)$ & 0.977 \\
\hline
\end{tabular}


Table 5 Univariable analysis of antibiotic related variables by specialty

\begin{tabular}{|c|c|c|c|}
\hline & Medicine $162 n(\%)$ & Surgery 164 n (\%) & $p$ value * \\
\hline Total number of courses of antibiotics & 395 & 461 & - \\
\hline \multicolumn{4}{|c|}{ Route of antibiotics (as a total of all courses) } \\
\hline Intravenous & $200(51)$ & $395(86)$ & \multirow[t]{2}{*}{$<0.001$} \\
\hline Oral & 195(49) & $66(14)$ & \\
\hline \multicolumn{4}{|l|}{ Number of antibiotics during spell } \\
\hline 1 & $36(22.22)$ & $12(7.32)$ & \multirow[t]{3}{*}{0.001} \\
\hline 2 & $52(32.10)$ & $68(41.46)$ & \\
\hline$\geq 3$ & $74(45.68)$ & $84(51.22)$ & \\
\hline \multicolumn{4}{|l|}{ Antibiotic exposure days } \\
\hline $1-3$ days & $65(40)$ & $56(34)$ & \multirow[t]{4}{*}{0.134} \\
\hline 4-7 days & $55(34)$ & $52(32)$ & \\
\hline 7-14 days & $28(17)$ & $33(20)$ & \\
\hline$\geq 15$ & $14(9)$ & $23(14)$ & \\
\hline \multicolumn{4}{|l|}{ Cumulative antibiotic days } \\
\hline $1-7$ days & $94(58)$ & $70(43)$ & \multirow[t]{3}{*}{0.016} \\
\hline 8-14 days & $46(28)$ & $44(27)$ & \\
\hline$\geq 15$ & $22(14)$ & $50(30)$ & \\
\hline \multicolumn{4}{|l|}{ Antibiotic rank } \\
\hline Narrow & $11(6.79)$ & $6(3.66)$ & \multirow[t]{4}{*}{0.507} \\
\hline Broad & $98(60.49)$ & $95(57.93)$ & \\
\hline Extended & $47(29.00)$ & $56(34.15)$ & \\
\hline Restricted & $6(3.70)$ & $7(4.27)$ & \\
\hline \multicolumn{4}{|l|}{ Change to initial antibiotic course } \\
\hline No change/discontinued & $76(46.91)$ & $90(54.88)$ & \multirow[t]{3}{*}{0.0037} \\
\hline Antibiotic escalated & $31(19.14)$ & $49(29.88)$ & \\
\hline Antibiotic de-escalated & $55(33.95)$ & $25(15.24)$ & \\
\hline \multicolumn{4}{|l|}{ Antibiotic compliant to local policy } \\
\hline Yes & $131(80.86)$ & $108(65.85)$ & \multirow[t]{3}{*}{$<0.001$} \\
\hline No & $30(18.52)$ & $35(21.34)$ & \\
\hline Unclear & $1(0.62)$ & $21(12.80)$ & \\
\hline \multicolumn{4}{|c|}{ Antibiotic compliant to local policy ('unclear' treated as missing) } \\
\hline Yes & $131(81.37)$ & $108(75.52)$ & \multirow[t]{2}{*}{0.215} \\
\hline No & $30(18.63)$ & $35(24.48)$ & \\
\hline \multicolumn{4}{|l|}{ Antibiotic prescribed on discharge } \\
\hline Yes & $80(49)$ & $73(45)$ & \multirow[t]{3}{*}{0.677} \\
\hline No & $67(41)$ & $74(45)$ & \\
\hline No data/Patient died & $15(9)$ & $17(10)$ & \\
\hline
\end{tabular}

* $P$ values calculated using Pearson Chi-Squared test or Fisher's exact test

escalation of antibiotic use, suggesting that de-escalation can lead to reduced length of stay [31, 32]. The reverse can also be expected, that patients who have their antibiotic therapy escalated can be more ill and therefore in need of remaining in hospital. Antibiotic prescribing in the surgical team was also more likely to be non-complaint to local policy and guidelines. The medical specialty were more consistent in providing a rationale and indication for prescribed antibiotics. Including the unclear category in the analysis was important to illustrate the lack of documented indication for antibiotic therapy in surgery. The local policy stipulates that an indication must be documented for prescribed antibiotics. A missing indication could also be classed as inappropriate and therefore non- 
Table 6 Multiple logistic regression examining the association between escalating antibiotic therapy and the selected variables, adjusting for specialty $(n=326)$

\begin{tabular}{|c|c|c|c|c|c|c|}
\hline & OR & $95 \% \mathrm{Cl}$ & Crude P & Adjusted $\mathrm{OR}^{\mathrm{a}}$ & $95 \% \mathrm{Cl}$ & $\begin{array}{l}\text { Adjusted } \\
P \text { value }\end{array}$ \\
\hline \multicolumn{7}{|l|}{ Specialty } \\
\hline Medicine & 1 & & & 1 & & \\
\hline Surgery & 1.801 & $1.076-3.013$ & 0.024 & 1.942 & $1.067-3.534$ & 0.030 \\
\hline \multicolumn{7}{|l|}{ Comorbidity score } \\
\hline Low & 1 & & & 1 & & \\
\hline Mod & 1.164 & $0.629-$ & 0.629 & 0.845 & $0.402-1.773$ & 0.655 \\
\hline Severe & 1.380 & $\begin{array}{l}2.151 \\
0.741-2.570\end{array}$ & 0.310 & 1.123 & $0.541-2.354$ & 0.747 \\
\hline \multicolumn{7}{|c|}{ Culture and sensitivity } \\
\hline Negative & 1 & & & 1 & & \\
\hline Positive & 0.569 & $0.236-$ & 0.209 & 0.583 & $0.218-1.559$ & 0.282 \\
\hline No culture & 0.378 & $\begin{array}{l}1.371 \\
0.192-0.746\end{array}$ & 0.005 & 0.470 & $0.219-1.009$ & 0.053 \\
\hline \multicolumn{7}{|l|}{ Los } \\
\hline $1-7$ & 1 & & & 1 & & \\
\hline $8-14$ & 2.027 & $0.998-$ & 0.051 & 2.012 & $0.962-4.215$ & 0.064 \\
\hline$\geq 15$ & 5.758 & $\begin{array}{l}4.117 \\
3.137-10.567\end{array}$ & $<0.001$ & 5.138 & $2.66-9.910$ & $<0.001$ \\
\hline \multicolumn{7}{|c|}{ Sign of infection on chest $\mathrm{X}$-ray } \\
\hline No & 1 & & & 1 & & \\
\hline Yes & 1.145 & $0.563-$ & 0.709 & 1.405 & $0.635-3.109$ & 0.402 \\
\hline No chest X-ray & 0.486 & $\begin{array}{l}2.323 \\
0.273-0.863\end{array}$ & 0.014 & 0.610 & $0.328-1.173$ & 0.142 \\
\hline
\end{tabular}

${ }^{a}$ Adjusted for all other variables included within this table

compliant to the local policy. Including the 'unclear' category in the analysis accommodated for this deviation from policy.

This study was conducted alongside an in-depth qualitative ethnographic research that described the contextual differences in decision-making between the teams $[6,7]$ and identified key differences in how these teams prioritise antibiotic decision-making. The qualitative research reported a model of individualism in surgery, where surgeons driven by performance metrics, are less willing to tolerate uncertainty in antibiotic decision-making [6]. The qualitative findings add value and provide contextual insights to better understand the quantitatively measured antibiotic decision-making behaviours, describe in this cohort study. Practicing a defensive prescribing approach in surgery, and less comfortable with uncertainty in the decisions made for the patients, surgeons may try to avert the risk of a patient developing infections by prescribing broad-spectrum antibiotics. Additionally, the qualitative findings identified the surgical teams to be willing to delegate antibiotic decision-making to the junior staff or other specialties $[6,7]$. This can be leveraged to develop better collaborations between stewardship and surgical teams to ensure that antibiotic prescribing in surgery can be optimised.

There are several key recommendations from this study that can be used to develop bespoke stewardship interventions. Antibiotic stewardship interventions in surgery should focus on the post-operative period or in patients who are under surgical care for longer durations, as they are more likely to be on more broadspectrum antibiotics and to receive multiple courses. Across both specialties more focus needs to be placed on ensuring the correct microbiology tests are performed prior to initiating antibiotic therapy. This can help support correct diagnosis earlier in medial patients to a more targeted spectrum of therapies, and in surgical patients in can help teams with being able to correctly diagnose infections and provide an indication for the prescribed antibiotics.

\section{Limitations}

This is a single-center study focusing on two general medical and surgical teams. The data may therefore not 
be representative of the breadth of hospital specialties. The cohorts of general medicine and surgery may not be comparable in terms of infection etiology. To address this, one of the primary outcome measures was compliance to policy. This adjusted for the variation between the cohorts, as regardless of the cause of infection the antibiotic therapy would be expected to the compliant to the local policy recommendation for the indication. Since the sample size required to address the research questions was small it was not feasible to include a broad number of infections in the analysis. The inaccuracies of ICD-10 coding have been reported [33]. Any inaccuracies in the coding will have an impact on the ACCI score derived for the patients in this study. For the multivariate regression analysis performed, independent variables that were not available through the data collection methods used, such as infection markers at end of antibiotic therapy could affect prescribing outcomes that were not included in this model. The aforementioned model only includes chest X-ray as a radiological measure. If all the forms of potential diagnostic tests were included, there would be too many categories to consider, for which missing data would be high across different infection-types, and therefore we utilized the most commonly performed diagnostic test.

\section{Conclusion}

One in five patients (across surgery and medicine) were prescribed antibiotics in the absence of raised white cell count or a fever. There is no difference in the spectrum of antibiotics prescribed between medicine and surgery. Surgical patients are significantly more likely to a) receive a greater number of courses of antibiotics; b) have their initial therapy escalated; and c) be on a course not in line with local policy. There are opportunities to widen the reach of ASP and focus on perioperative care, focusing on the review of antibiotic prescriptions in the post-operative phase.

\section{Abbreviations}

ASP: Antimicrobial stewardship programmes; CCl: Charlson comorbidity index; Cl: Confidence interval; ED: Emergency department; OR: Odds ratio

\section{Acknowledgments}

$\mathrm{AH}$ acknowledges the support of the Imperial College Healthcare Trust NIHR Biomedical Research Centre (BRC). The authors acknowledge the help of all the staff and patients in the general medical and surgical teams, without whose co-operation and assistance this study would not have been possible.

\section{Authors' contributions \\ $E C, E D$, and AH developed the study design. EC collected the data and conducted the analysis. DG and NN provided statistical analysis input. MG and TR provided input into study design. The first draft of the manuscript was written by EC. Subsequent versions had input from all co-authors. All authors read and approved the final manuscript.}

\section{Funding}

This work was partially funded by: 1) Economic and Social Science Research Council (ESRC) as part of the Antimicrobial Cross Council initiative [ES/
P008313/1] supported by the seven UK research councils, and the Global Challenges Research Fund and the National Institute for Health Research, and by 2) the National Institute for Health Research Health Protection Research Unit (NIHR HPRU) in Healthcare Associated Infections and Antimicrobial Resistance at Imperial College London in partnership with Public Health England (PHE) in collaboration with The Sanger Institute, the University of Cambridge Veterinary School and Imperial College Health Partners. The views expressed are those of the author(s) and not necessarily those of the NHS, the NIHR, the Department of Health or Public Health England. DG is funded by a Wellcome Trust Clinical PhD award.

\section{Availability of data and materials}

Data cannot be shared publicly because of confidentiality. Data are available from the Imperial College Institutional Data Access / Ethics Committee (contact via Esmita Charani) for researchers who meet the criteria for access to confidential data.

Ethics approval and consent to participate

Ethical approval for this study was granted by National Health Service (NHS) (England) Research Ethics Committee (IRAS ID 176038).

\section{Consent for publication}

Not applicable.

\section{Competing interests}

The authors declare that they have no competing interests.

\section{Author details}

${ }^{1} \mathrm{NIHR}$ Health Protection Research Unit in Healthcare Associated Infections and Antimicrobial Resistance, Hammersmith Campus, Imperial College London, 8th Floor Commonwealth Building, Du Cane Road, London W12 ONN, UK. ${ }^{2}$ Royal College of Surgeons in Ireland, RCSI Education \& Research Centre, Beaumont Hospital, Beaumont, Dublin 9, Ireland. ${ }^{3}$ Department of Biostatistics and Epidemiology, School of Public Health, Imperial College London, London W2 1PG, UK. ${ }^{4}$ Department of Pharmacy, Imperial College Healthcare NHS Trust, St Mary's Hospital, Praed Street, London W12 1NY, UK.

Received: 25 June 2019 Accepted: 30 August 2019

Published online: 13 September 2019

\section{References}

1. Cosgrove SE. The relationship between antimicrobial resistance and patient outcomes: mortality, length of hospital stay, and health care costs. Clin Infect Dis. 2006;42(Suppl 2):S82-9.

2. Aldeyab MA, Kearney MP, McElnay JC, Magee FA, Conlon G, MacIntyre J, et al. A point prevalence survey of antibiotic use in four acute-care teaching hospitals utilizing the European surveillance of antimicrobial consumption (ESAC) audit tool, Vol 140. Epidemiol Infect. 2012;140(9):1714-20.

3. Zarb P, Goossens H. European surveillance of antimicrobial consumption (ESAC): value of a point-prevalence survey of antimicrobial use across Europe. Drugs. 2011;71(6):745-55.

4. Fridkin S, Baggs J, Fagan R, Magill S, L a P, Malpiedi P, et al. Vital signs: improving antibiotic use among hospitalized patients. MMWR Morb Mortal Wkly Rep. 2014;63(9):194-200.

5. Rawson TMT, Butters TPT, Moore LLSP, Castro-Sánchez E, Cooke FFJ, Holmes $\mathrm{AAH}$. Exploring the coverage of antimicrobial stewardship across UK clinical postgraduate training curricula. J Antimicrob Chemother. 2016;71(11):3284-92.

6. Charani E, Ahmad R, Rawson T, Castro-Sanchez E, Tarrant C, Holmes A. The differences in antibiotic decision-making between acute surgical and acute medical teams - an ethnographic study of culture and team dynamics. Clin Infect Dis. 2018. https://doi.org/10.1093/cid/ciy844 [Epub ahead of print].

7. Charani E, Tarrant C, Moorthy K, Sevdalis N, Brennan L, Holmes AHH. Understanding antibiotic decision making in surgery - a qualitative analysis. Clin Microbiol Infect. 2017;23(10):752-60.

8. Wiegmann DA, Sundt TM. Workflow disruptions and surgical performance: past, present and future. BMJ Qual Saf. 2019.pii:bmjqs-2018-008670. https:// doi.org/10.1136/bmjqs-2018-008670. [Epub ahead of print0.

9. J a T, Naik VN, Lingard L, Sussman JA, Mccaffrey CB, Leary DB, et al. Exploring obstacles to proper timing of prophylactic antibiotics for surgical site infections. Qual Saf Health Care. 2006;15(1):32-8. 
10. Charani E, Gharbi M, Moore LSP, Castro-Sanchéz E, Lawson W, Gilchrist M, et al. Effect of adding a mobile health intervention to a multimodal antimicrobial stewardship programme across three teaching hospitals: an interrupted time series study. J Antimicrob Chemother. 2017;72(6):1825-31.

11. Jones SR, Carley S, Harrison M. An introduction to power and sample size estimation. Emerg Med J. 2003;20(5):453-8.

12. Charlson ME, Szatrowski TP, Peterson J, Gold J. Validation of a combined comorbidity index. J Clin Epidemiol. 1994;47:1245-51.

13. Murray SB, Bates DW, Ngo L, Ufberg JW, Shapiro NI. Charlson index is associated with one-year mortality in emergency department patients with suspected infection. Acad Emerg Med. 2006;13(5):530-6.

14. Stevens V, Dumyati G, Fine LS, Fisher SG, Van Wijngaarden E. Cumulative antibiotic exposures over time and the risk of clostridium difficile infection. Clin Infect Dis. 2011;53(1):42-8.

15. Braykov NP, Morgan DJ, Schweizer ML, Uslan DZ, Kelesidis T, Weisenberg SA, et al. Assessment of empirical antibiotic therapy optimisation in six hospitals: an observational cohort study. Lancet Infect Dis. 2014;14(12):1220-7.

16. Kollef MH, Morrow LE, Niederman MS, Leeper KV, Anzueto A, Benz-Scott L, et al. Clinical characteristics and treatment patterns among patients with ventilator-associated pneumonia. Chest. 2006;129(5):1210-8.

17. Szymczak JE. Are surgeons different ? The case for bespoke antimicrobial stewardship. Clin Infect Dis. 2018;2(Xx):1-3.

18. Davey P, Marwick CA, Scott CL, Charani E, Mcneil K, Brown E, et al. Interventions to improve antibiotic prescribing practices for hospital inpatients. Cochrane Database Syst Rev. 2017;(2017):2.

19. Department of Health. Start smart - then focus antimicrobial stewardship toolkit for English hospitals about Public Health England. 2014.

20. Ingram PR, Seet JM, Budgeon CA, Murray R. Point-prevalence study of inappropriate antibiotic use at a tertiary Australian hospital. Intern Med J. 2012;42:719-21.

21. Cusini A, Rampini SK, Bansal V, Ledergerber B, Kuster SP, Ruef C, et al. Different patterns of inappropriate antimicrobial use in surgical and medical units at a tertiary care hospital in Switzerland: a prevalence survey. PLoS One. 2010;5(11):1-8.

22. Hecker MT, Aron DC, Patel NP, Lehmann MK, Donskey CJ. Unnecessary use of antimicrobials in hospitalized patients. Arch Intern Med. 2003;163(8):972.

23. Masterton RG. Antibiotic De-Escalation. Crit Care Clin. 2011;27:149-62.

24. De Waele JJ, Ravyts M, Depuydt P, Blot SI, Decruyenaere J, Vogelaers D. De-escalation after empirical meropenem treatment in the intensive care unit: fiction or reality? J Crit Care. 2010;25(4):641-6.

25. Ackland GL, Scollay JM, Parks RW, De Beaux I, Mythen MG. Pre-operative high sensitivity C-reactive protein and postoperative outcome in patients undergoing elective orthopaedic surgery. Anaesthesia. 2007;62(9):888-94.

26. Cole DS, Watts A, Scott-Coombes D, Avades T. Clinical utility of perioperative C-reactive protein testing in general surgery. Ann R Coll Surg Engl. 2008;90(4):317-21.

27. Ørn S, Manhenke C, Ueland T, Dams JK, Mollnes TE, Edvardsen T, et al. C-reactive protein, infarct size, microvascular obstruction, and leftventricular remodelling following acute myocardial infarction. Eur Heart J. 2009;30(10):1180-6.

28. Martins OM, Fonseca VF, Borges I, Martins V, Portal VL, Pellanda LC. Creactive protein predicts acute myocardial infarction during high-risk noncardiac and vascular surgery. Clinics. 2011;66(5):773-6.

29. Arroyo-Espliguero R, Avanzas P, Cosín-Sales J, Aldama G, Pizzi C, Kaski JC C-reactive protein elevation and disease activity in patients with coronary artery disease. Eur Heart J. 2004;25(5):401-8.

30. Lelubre C, Anselin S, Boudjeltia KZ, Biston P, Piagnerelli M. Interpretation of C-reactive protein concentrations in critically ill patients. Biomed Res Int. 2013;2013:124021.

31. Viasus D, Simonetti AF, Garcia-Vidal C, Niubó J, Dorca J, Carratalà J. Impact of antibiotic de-escalation on clinical outcomes in community-acquired pneumococcal pneumonia. J Antimicrob Chemother. 2017;72(2):547-53.

32. Liu P, Ohl C, Johnson J, Williamson J, Beardsley J, Luther V. Frequency of empiric antibiotic de-escalation in an acute care hospital with an established antimicrobial stewardship program. BMC Infect Dis. 2016;16(1):751.

33. Mahbubani K, Georgiades F, Goh EL, Chidambaram S, Sivakumaran P, Rawson T, et al. Clinician-directed improvement in the accuracy of hospital clinical coding. Futur Healthc. 2018;5(1):47-51.

\section{Publisher's Note}

Springer Nature remains neutral with regard to jurisdictional claims in published maps and institutional affiliations.
Ready to submit your research? Choose BMC and benefit from:

- fast, convenient online submission

- thorough peer review by experienced researchers in your field

- rapid publication on acceptance

- support for research data, including large and complex data types

- gold Open Access which fosters wider collaboration and increased citations

- maximum visibility for your research: over $100 \mathrm{M}$ website views per year

At BMC, research is always in progress.

Learn more biomedcentral.com/submissions 